\title{
O PRAGMATISMO CLÁSSICO E A DIMENSÃO SOCIAL DO CONHECIMENTO*
}

\author{
Classical Pragmatism and the Social Dimension of Knowledge
}

Daniel Cerqueira Baiardi**

Resumo: Neste artigo, são realçadas algumas das principais teses do pragmatismo clássico que confrontam a epistemologia tradicional de cunho individualista. A partir de uma reconstrução histórica do cenário intelectual de William James e Charles S. Peirce, ofereço uma distinção entre as duas tendências principais deste movimento filosófico tão relevante para o pensamento contemporâneo. Neste processo, argumento que esta é uma tradição de pesquisa definitivamente comprometida com os efeitos da comunidade sobre a formação e fixação das crenças. Por fim, faço algumas rápidas considerações a respeito de algumas perspectivas pragmatistas sobre a comunidade científica.

Palavras-chave: Comunidade Científica. Epistemologia Social. Pragmatismo Clássico. Pragmaticismo. Psicologia Cognitiva.

\begin{abstract}
In this article, are highlighted some of the main theses of classical pragmatism that confront traditional epistemology individualistic nature. From a historical reconstruction of the intellectual scenario of William James and Charles S. Peirce, I offer a distinction between the two main trends of this so relevant philosophical movement to contemporary thinking. In this process, I argue that this is a tradition of research definitely committed with the effects of community on the formation and fixation of beliefs. Finally, I make some brief remarks about some pragmatists' views on the scientific community.
\end{abstract}

Keywords: Classical Pragmatism. Cognitive Psychology. Pragmaticism. Scientific Community. Social Epistemology.

\footnotetext{
* Uma versão desse trabalho foi apresentada na I Conferência de Epistemologia Social sediada na PUC-RS, 22-24 maio de 2012. Aproveito o ensejo para agradecer à organização do evento, em especial, ao Prof. Tiegüe V. Rodrigues, por sua cordialidade. Também fico grato pelos comentários e conversas edificantes com o Prof. Gabriel J. C. Mograbi. Muito da forma atual desse artigo, mas não suas possíveis falhas, deve-se aos conselhos judiciosos do Prof. Vincent M. Colapietro.

** Doutorando em Filosofia pela Universidade Federal da Bahia (UFBA); Visiting Scholar na Universidade Estadual da Pensilvânia (Penn State). Bolsista PDSE-CAPES (processo N² 2867-13-3). Contato: baiardi@usp.br
}

\begin{tabular}{|c|c|c|c|c|c|}
\hline intuitio & $\begin{array}{c}\text { ISSN } \\
1983-4012\end{array}$ & Porto Alegre & Vol.7 $-\mathrm{N}^{\mathrm{o}} .2$ & $\begin{array}{c}\text { Novembro } \\
2014\end{array}$ & p. 134-145 \\
\hline
\end{tabular}




\section{Introdução}

Enfoco aqui um pragmatismo clássico representado por suas figuras-chave no momento de sua divulgação, Charles Sanders Peirce e William James. Como defendido por alguns críticos, o estudo de ambos autores fornece uma visão mais profunda e privilegiada dessa tradição ${ }^{1}$. Entretanto, o desenvolvimento do sistema peirceano, orientado por seu realismo escolástico, acaba por constituir uma doutrina distinta, a qual ele preferiu denominar pragmaticismo, no intuito de diferenciá-la do caminho nominalista tomado por James e F. C. S. Schiller. Não obstante, Peirce e James lançaram bases para uma ampla tradição de pesquisa comprometida com a pluralidade metodológica e com a diversidade dos pontos de vista. Peirce ficou reconhecido como idealizador do pragmatismo, e James, enquanto seu principal divulgador ${ }^{2}$. Contudo, o próprio Peirce fez questão de dividir os créditos com os membros do Metaphysical Club. De acordo com Peirce, foi nas discussões que se sucediam no clube que veio à luz a “ideia viva” do pragmatismo. Devido ao meu recorte histórico, negligenciarei neste relato as colaborações de outros intelectuais que ofereceram contribuições significativas a essa tradição, como John Dewey, F. C. S. Schiller e George H. Mead. Darei ênfase assim à primeira geração, pois, ainda que admitindo a genialidade de Peirce e o esforço quase messiânico de James, minha intenção aqui é reforçar a ideia de que nenhuma abelha em uma colmeia pode encarar o fruto de seu trabalho e dizer "este mel fi-lo eu", parafraseando Saramago ${ }^{3}$. Peirce é ainda mais categórico quando defende que "o progresso da ciência não pode continuar sem colaboração [...] nenhuma mente pode dar um passo sem o auxílio de outras mentes"4.

O clube reuniu-se pela primeira vez em Cambridge, Massachusetts, no inverno de 1872. Possuía uma cláusula que impedia qualquer ação do grupo enquanto corpo coletivo, tratava-se de uma união de mentes inquietas do círculo de Harvard e tinham algumas importantes ideias em comum. A associação não possuía secretários, nem mesmo qualquer tipo de registro sobre o que seus membros discutiam ${ }^{5}$. Por esses fatores, entendemos melhor as razões pelas quais existem tão poucos relatos do que acontecia no Metaphysical Club. Quanto aos membros em sua formação, podemos elencar, além de Peirce, James e Chauncey Wright: Nicholas St. John Green e Joseph Bangs Warner, ambos advogados de Cambridge; Oliver Wendell Holmes Jr., mais tarde chefe da Suprema Corte de Justiça dos Estados Unidos; ainda que ocasionalmente presente, John Fiske, historiador, filósofo e evolucionista de inclinação spenceriana;

${ }^{1}$ HOUSER, N. (2011) Peirce Post-Jamesian Pragmatism In: European Journal of Pragmatism and American Philosophy, 2011, p. 44.

${ }^{2}$ Não há consenso absoluto nessa matéria, para a perspectiva de uma gênese jamesiana ver PERRY, 1964, p. 409

${ }^{3} \mathrm{O}$ insight é proveniente do romance $O$ Evangelho Segundo Jesus Cristo.

${ }^{4}$ PEIRCE, 1903, em Collected Papers of Charles Sanders Peirce, volume 2, parágrafo 220, daqui em diante sigo a forma convencionada de citação desta obra, como exemplo, faria referência ao mesmo trecho como: CP 2.220, 1903.

${ }^{5}$ BRENT, J. (1993) Charles Sanders Peirce: A Life. Indiana University Press; Bloomington, 1993, p. 84.

\begin{tabular}{|c|c|c|c|c|c|}
\hline intuitio & $\begin{array}{c}\text { ISSN } \\
1983-4012\end{array}$ & Porto Alegre & Vol.7 $-\mathrm{N}^{\mathrm{o}} .2$ & $\begin{array}{c}\text { Novembro } \\
2014\end{array}$ & p. 134-145 \\
\hline
\end{tabular}


Francis Ellingwood Abbot, filósofo famoso por aplicar o método científico à teologia; Henry Bowen, professor do Departamento de Filosofia de Harvard; e, por fim, C. C. Everett da Divinity School ${ }^{6}$.

Wright era uma espécie de mentor para a maioria dos membros, sua influência sobre os jovens foi notória e ainda ofereceu como que um princípio guia para o pragmatismo. Ele os convenceu seus colegas de que as discussões mais proveitosas são, na verdade, verdadeiras aproximações a outras mentes, em um esforço de entender como outros veem o mundo. Na opinião de Wright, esta prática se demonstrava muito mais fértil do que a mera dissecação de proposições ${ }^{7}$. Esta inclinação para uma apreciação psicológica das crenças seria uma marca da aproximação pragmatista. Wright além de debruçar-se sobre as disposições industriosas das abelhas e muitos outros temas, também se dedicou a explicar a evolução da autoconsciência, termo muito caro para muitos metafísicos pós-kantianos e hegelianos, os quais não só davam pouco crédito, mas também desprezavam a psicologia individualista, a qual era para eles, uma doutrina que não conseguia captar "a mentalidade objetiva" dos grupos sociais e das instituições ${ }^{8}$.

O pragmatismo, que nasceu no clube de Cambridge, revelou-se como a tradição que mais ofereceria críticas duras contra uma epistemologia individualista. No interior do pragmatismo clássico, encontramos um confrontamento com a complexidade do mundo real como, muito provavelmente, nunca antes fora empreendido. O pragmatismo clássico "ataca o preconceito antigo da singularidade humana na sua mais protegida fortaleza, aquela construída pela lógica clássica e pela epistemologia tradicional"9. O pragmatismo é um fruto do seu tempo. O século XIX foi palco de rápidos avanços para as ciências empíricas, as quais progrediam em passos largos, impulsionadas por financiamentos do Estado e sob os auspícios de grandes instituições. Diante disso, os pragmatistas clássicos assumiram uma postura de desconfiança frente à veracidade última das teorias. Com efeito, os pragmatistas tiveram a clareza de assumir esse contínuo avanço em sua concepção de verdade, percebendo que essas rápidas mudanças de crenças no interior da comunidade científica poderiam abalar, inclusive, as ciências formais.

Em alguns círculos, o pragmatismo é encarado enquanto método e em outros como uma epistemologia ${ }^{10}$. De uma forma ou de outra, as duas principais tendências de pragmatismo oferecem uma teoria da verdade, ainda que, no caso de James, mais controvertida, sustentada por uma sofisticada teoria da significação. Esta teoria é construída a partir da célebre máxima de Peirce em torno do significado: "Considere que efeitos, os quais possam ter concebíveis consequências práticas, nós concebemos que o

\footnotetext{
${ }^{6}$ BRENT, J. (1993) Charles Sanders Peirce: A Life. Indiana University Press; Bloomington, 1993, p. 83; MENAND, 2011, p. 215-6.

${ }^{7}$ WRIGHT, C. em carta à F. E. Abbot, 28 de outubro de 1867, apud WIENER, P. (1969) Evolution and the Founders of Pragmatism. Peter Smith: Gloucester, 1969, p. 30.

${ }^{8}$ WIENER, P. (1969) Evolution and the Founders of Pragmatism. Peter Smith: Gloucester, 1969, p. 54.

9 FREGA, R. (2011) Evolutionary Prolegomena to a Pragmatist Epistemology of Belief. In FREGA, R. (Ed.) Pragmatist Epistemologies. Lanham: Lexington Books, 2011, 2011, p. 130.

${ }^{10}$ HOUSER, N. (2011) Peirce Post-Jamesian Pragmatism In: European Journal of Pragmatism and American Philosophy, 2011, p. 42.
}

\begin{tabular}{|c|c|c|c|c|c|}
\hline intuitio & $\begin{array}{c}\text { ISSN } \\
1983-4012\end{array}$ & Porto Alegre & Vol.7 $-\mathrm{N}^{\mathrm{o}} .2$ & $\begin{array}{c}\text { Novembro } \\
2014\end{array}$ & p. 134-145 \\
\hline
\end{tabular}


objeto de nossa percepção possua. Então, nossa concepção desses efeitos constitui a totalidade de nossa concepção desse objeto"11 . A partir desse núcleo duro, tanto na direção traçada por Peirce, quanto naquela esboçada por James, encontramos uma teoria da ação, projetada pelos propósitos do indivíduo, assim como, uma teoria do conhecimento, descentralizada e voltada para a incorporação de aspectos sociais na construção do significado e na elaboração de sua concepção de verdade. Com efeito, um dos objetivos centrais do pragmatismo é construir uma teoria da mediação entre agentes orientados por interesses, inseridos em um mundo pluralístico e processual ${ }^{12}$.

$\mathrm{Na}$ teoria da investigação pragmatista, encontra-se um acirrado compromisso com a descrição do processo de formação das crenças. O conceito de crença é introduzido de maneira emblemática no Metaphysical Club a partir de discussões sobre a psicologia de Alexander Bain por Green. Para Peirce, o que mais chamava atenção na definição de Bain é a insistência em que aquilo que um homem realmente acredita é, exatamente, o que o motiva à ação ${ }^{13}$.

Nicholas St. John Green era um dos mais interessados membros, um advogado habilidoso e letrado, um discípulo de Jeremy Bentham. Seu extraordinário poder de despir a verdade quente e ofegante das roupagens de fórmulas há muito tempo usadas, era a razão dele atrair atenção em todos os círculos. Em particular, ele insistiu na importância de aplicar a definição de crença de Bain, como "aquela sobre a qual um homem está disposto a agir". A partir dessa definição, o pragmatismo não é nada mais que um corolário $^{14}$

Peirce, como comentado, a princípio, sugere que a teoria de Green sobre crenças fosse denominada pragmatismo, termo emprestado de uma passagem da Crítica, onde Kant denomina uma crença contingente, como a de um médico que deve agir rapidamente, na esperança de salvar seu paciente, enquanto uma crença pragmática [pragmatischen Glauben]. Vale lembrar que é de suma importância atentar aqui para a distinção entre a fixação da crença e sua justificação dentro deste quadro conceitual. Enquanto a fixação está diretamente conectada com os efeitos concebíveis de sustentação da crença, a justificação se relaciona, mais profundamente, com a prática social de garantir a sua legitimação lógica.

\footnotetext{
${ }^{11}$ CP 5.402, 1878. No original: "Consider what effects, which might conceivably have practical bearings, we conceive the object of our conception to have. Then, our conception of the effects is the whole of our conception of the object." PEIRCE, 1878, p. 293. Publicado pela primeira vez no artigo: "How to Make Our Ideas Clear", Popular Science Monthly, v. 12, pp. 286-302.

${ }^{12}$ MCDERMOTT, J. J. (1977) Introduction. In: MCDERMOTT, J. J. (Ed.) The Writings of William James: A Comprehensive Edition. Chicago: The University of Chicago Press, 1977, p. xli

13 BRENT, J. (1993) Charles Sanders Peirce: A Life. Indiana University Press; Bloomington, 1993, p. 58; MENAND, L. (2001). The Metaphysical Club; a Story of Ideas in America. Nova York: Farrar, Straus and Giroux Eds., 2001, p. 225.

${ }^{14}$ CP 5.12, c. 1906.
}

\begin{tabular}{|c|c|l|l|c|c|}
\hline intuitio & $\begin{array}{c}\text { ISSN } \\
1983-4012\end{array}$ & Porto Alegre & Vol.7 $-\mathrm{N}^{\circ} .2$ & $\begin{array}{c}\text { Novembro } \\
2014\end{array}$ & p. 134-145 \\
\hline
\end{tabular}




\section{0 pragmatismo humanista de James}

James introduziu à ideia seminal de Peirce uma visão intensamente humanista, uma doutrina que, no meu entender, é desenvolvida no interior da intensa vida intelectual de James, um sofisticado denominador comum entre sua educação nas artes e sua formação científica. Entretanto, vale ressaltar que esse é um humanismo que não pode ser confundido com antropocentrismo. Outra característica marcante na filosofia de James é seu holismo. James, assim como Peirce, rejeitou muitos dualismos famosos como fato e valor, eventos internos e externos, entre outros, todos considerados por James como “interdependentes e interpenetráveis"

Em 1878, James apresenta publicamente sua concepção de mente, através de uma crítica à definição de Herbert Spencer, fórmula a qual adiciona a noção de interesse ou intencionalidade. Esta continuidade, da filosofia da mente de James frente às teorias desenvolvimentistas, foi recentemente reavaliada por Dennett e Fodor, os quais consideram o programa evolucionista, no final do século XIX, como um empreendimento completamente distinto da ortodoxa aproximação intelectualista ${ }^{16}$. No início do The Principles of Psychology (1890), James esclarece que seu projeto tem por objetivo algo distinto de uma psicologia completamente centrada no sujeito.

No geral, poucas fórmulas recentes têm feito um maior real serviço, conquanto incompleto, do que o spencerianismo, segundo o qual a essência da vida mental e corporal é, a saber, "o ajustamento de relações internas às externas". Esta fórmula é a vagueza encarnada; mas devido ao fato da mente habitar ambientes que agem sobre ela e sobre os quais ela por sua vez reage [...] coloca a mente no interior de todas as suas relações concretas, ela é imensamente mais fértil do que a antiquada "psicologia racional" a qual trata a alma como existente de forma desconexa, suficiente em si mesma, propondo-se a considerar somente sua natureza e suas propriedades ${ }^{17}$.

Apesar de Spencer ter ficado célebre por seu trabalho pioneiro na sociologia, não conseguiu entrever, na visão de James, a importância das convenções sociais para a formação das crenças. Apesar do interesse na sobrevivência predominar entre os demais, desfrutando de posição primus inter pares, na opinião de James, não é o único que opera na teleologia do indivíduo. Em seu ponto de vista, seria algo por demais simplificado. Em um termo como mente, James vê uma série de fenômenos distintos, fenômenos que, sob sua ótica, obedecem a diferentes leis: lógicas, morais, estéticas, imaginativas, entre outras. Sob tais prerrogativas, James sugere uma modificação na fórmula de Spencer, contemplando não

\footnotetext{
${ }^{15}$ PUTNAM, H. (1995) Permanência em James (Trad. de FOSCHIANI, C.) In: Cognitio-Estudos, V. 7, № 2, JulhoDezembro, 2010, pp. 210-220, p. 211.

16 DENNETT, D. C. (1982) Beyond Belief. In: WOODFIELD, A. (ed.) Thought and Object: Essays on intentionality. Oxford: Clarendon Press, p. 39; FODOR, J. A. (1980) Methodological Solipsism Considered as a Research Strategy in Cognitive Psychology. In: FODOR, J. A. Representations: Philosophical Essays on the Foundations of cognitive Science. Brighton: Harvester Press, 1981, p. 229-30.

${ }^{17}$ JAMES, W. The Principles of Psychology. Vol. I. New York: Henry Holt and Company, 1890, p. 6.
}

\begin{tabular}{|c|c|c|c|c|c|}
\hline intuitio & $\begin{array}{c}\text { ISSN } \\
1983-4012\end{array}$ & Porto Alegre & Vol.7 $-\mathrm{N}^{\mathrm{o}} .2$ & $\begin{array}{c}\text { Novembro } \\
2014\end{array}$ & p. 134-145 \\
\hline
\end{tabular}


somente os elementos ausentes na fórmula, mas também os anseios ideais, apontando para uma solução que pressupõe uma comunidade.

A excelência da mente individual consiste no estabelecimento de relações interiores cada vez mais extensivamente de acordo com os fatos externos da natureza, e aos anseios ideais dos indivíduos do seu grupo, sempre com um caráter voltado a promover a sobrevivência ou prosperidade física ${ }^{18}$.

Munido dessas concepções naturalizadas, de mente e cognição, James se lança para investigações de cunho propriamente epistemológico: a sua teoria da verdade, tomando o indivíduo enquanto parte de um corpo maior, o social. A verdade, insistia James, é uma noção que pressupõe uma comunidade e ele sustentava que fosse uma comunidade o mais ampla possível ${ }^{19}$. Considero que a análise da teleologia do indivíduo empreendida por James, imbricada por aspectos intersubjetivos, i.e., as influências do meio social, foi uma contribuição significativa não somente para a sua tradição filosófica de pesquisa, mas também para outros campos do conhecimento, em especial, para o estudo de disciplinas como a psicologia, a linguística e a sociologia.

A partir de sua posição radical, Rorty entende perfeitamente que, para James, nossa responsabilidade com a verdade não é capturar as coisas de maneira exata ${ }^{20}$. Antes disso, esta é uma responsabilidade para com nós mesmos de construir crenças que sejam coerentes umas com as outras, assim como para com nossos semelhantes e suas respectivas crenças. Entretanto, o que é bom para um grupo humano, muitas vezes, não é para outro grupo. Assim, algumas vertentes de pragmatismo, em especial de orientação jamesiana, deparam-se com o problema do relativismo. O que é verdade para um grupo humano, muitas vezes não é para outro. Será que a diversidade dos ambientes, dos contextos históricos e linguísticos, pode produzir verdades diferentes? Apesar dos pragmatistas contemporâneos assumirem que a natureza em si seja a mesma, consideram que os fenômenos se apresentam de formas variadas e os resultados práticos se mostram diferentes e, assim, concebem diferentemente devido às suas distintas experiências anteriores. De acordo com Rorty, James nunca conseguiu lidar satisfatoriamente com essa consequência contra intuitiva ${ }^{21}$.

Apesar de James sustentar que verdades são produzidas no curso da experiência do indivíduo, ele também sustenta a visão empirista que crenças verificadas concretamente por alguém são as bases de toda

18 JAMES, W. (1878) Remarks on Spencer's definition of Mind as Correspondence. In: Herbert Spencer, Contemporary Assessments - Herbert Spencer Collected Writings. Londres: Routledge \& Thoemmes Press, 1996, p. 8.

${ }^{19}$ PUTNAM, H. (1995) Permanência em James (Trad. de FOSCHIANI, C.) In: Cognitio-Estudos, V. 7, No 2, JulhoDezembro, 2010, pp. 210-220, p. 211.

20 RORTY, R. (2006) Uma visão pragmática da filosofia analítica contemporânea. In: RORTY, R \& GHIRALDELLI, P. Ensaios pragmatistas: sobre subjetividade e verdade. Lamparina: Rio de Janeiro, 2006, p. 85.

${ }^{21}$ RORTY, R. (1997) Religious Faith, Intellectual Responsibility and Romance. In: PUTNAM, Ruth Anna (Ed.) The Cambridge Companion to William James. Cambridge: Cambridge University Press, 1997, p. 85.

\begin{tabular}{|c|c|l|l|c|c|}
\hline intuitio & $\begin{array}{c}\text { ISSN } \\
1983-4012\end{array}$ & Porto Alegre & Vol.7 $-\mathrm{N}^{\circ} .2$ & $\begin{array}{c}\text { Novembro } \\
2014\end{array}$ & p. 134-145 \\
\hline
\end{tabular}


a superestrutura. De acordo com ele: "Todo o conhecimento humano torna-se discurso; trocamos ideias; fornecemos e buscamos verificações, tomando-as, uns dos outros, através do intercurso social”"22. A verdade, na concepção de James, é algo como um "bem” (e.g., a saúde). As verdades são "bens" devido ao fato de que nós podemos nos valer delas no futuro sem sermos insatisfatoriamente surpreendidos. Elas nos encaminham para universos verbais e conceituais úteis, assim como para termos sensíveis de uso prático: "Elas nos asseguram consistência, estabilidade e proporcionam uma fluente comunicação humana. Elas nos afastam ainda da excentricidade e do isolamento, do pensamento estéril e frustrante" ${ }^{23}$. Estas verdades, para ele, fazem parte de um sistema de créditos, desfrutando de aceitação no mercado enquanto não forem contestadas $^{24}$. Verdades são reduzidas a outras verdades e são avaliadas como valor de mercado. Rorty parece ter razão quando considera que "palavras e frases muito usadas e apreciadas não são abandonadas meramente porque seus usuários foram encurralados dialeticamente" ${ }^{25}$. Como em uma companhia de investimentos atribuímos valor a determinadas crenças e seus conceitos correlatos.

Como é possível perceber, a função psicológica do interesse em James se associa com sucesso à concepção de significado contido na máxima pragmatista peirceana. Contudo, James dá à fórmula de Peirce uma feição própria, ele sustenta que uma coisa é um grupo de qualidades que suscita interesse prático ou estético em nós e que damos nomes substantivos, enquanto que, a realidade significa simplesmente relações com nossa vida emocional e ativa. Qualquer coisa que excita e estimula nosso interesse é real. O humanismo de James assenta sua epistemologia sobre a própria constituição do que é humano, obedecendo aos princípios psicológicos e fisiológicos do então emergente paradigma naturalista, mas sem cair no reducionismo ${ }^{26}$.

\section{O Pragmaticismo de Peirce}

Como comentado, o pragmatismo de Peirce se desenvolveu e sofreu modificações importantes ao longo dos anos, justificando um novo nome, pragmaticismo. A aproximação de Peirce à realidade, ainda que consonante com a de James, está inserida em seu realismo sui generis, de cunho evolucionista e escolástico, assim como está também atrelada a sua teoria convergentista da verdade.

\footnotetext{
22 JAMES, W. (1907) Pragmatism's Conception of Truth. In: MCDERMOTT, J. J. (Ed.) The Writings of William James: A Comprehensive Edition. Chicago: The University of Chicago Press, 1977, p. 435.

${ }^{23}$ JAMES, W. (1907) Pragmatism's Conception of Truth. In: MCDERMOTT, J. J. (Ed.) The Writings of William James: A Comprehensive Edition. Chicago: The University of Chicago Press, 1977, p. 435.

${ }^{24}$ LOVEJOY, O. A. (1909) Pragmatism and Realism. In: The Journal of Philosophy, Psychology and Scientific Methods, Vol. 6, No. 21, pp. 575-580, p. 577.

25 RORTY, R. (2006) Uma visão pragmática da filosofia analítica contemporânea. In: RORTY, R \& GHIRALDELLI, P. Ensaios pragmatistas: sobre subjetividade e verdade. Lamparina: Rio de Janeiro, 2006, p. 109.

${ }^{26}$ BAIARDI, D. C. (2012) Intentionality, Fitness and Evolution in William James's Pragmatism. In: CognitioEstudos, V. 9, № 2, Julho-Dezembro, 2012, p. 105-8.
}

\begin{tabular}{|c|c|l|l|c|c|}
\hline intuitio & $\begin{array}{c}\text { ISSN } \\
1983-4012\end{array}$ & Porto Alegre & Vol.7 $-\mathrm{N}^{\circ} .2$ & $\begin{array}{c}\text { Novembro } \\
2014\end{array}$ & p. 134-145 \\
\hline
\end{tabular}


E o que queremos dizer com real? [...] O real, então, é aquilo que, cedo ou tarde, informação e raciocínio finalmente resultarão e, dessa forma é independente dos meus caprichos ou dos seus. Dessa forma, a própria origem da concepção de realidade envolve a noção de uma COMUNIDADE, sem limites definidos e capaz de um incremento indefinido de conhecimento [ênfase do autor] ${ }^{27}$.

$\mathrm{Na}$ fundação estrutural do sistema peirceano, na qual, o material usado nos lembra muito a aristotélica, ou seja, com elementos da experiência mesma, encontramos a sua lista de categorias. Contudo, a forma que seu projeto toma, revela-nos, com bastante clareza, sua arquitetura triádica. De acordo com Peirce, essa foi uma tentativa de caracterizar o que Hegel denominava "os três estágios do pensamento" e que corresponde às categorias encontradas nas quatro tríades da tábua de categorias de $\mathrm{Kant}^{28}$. As três categorias ontológicas da predicação de Peirce (qualidade, relação e representação) possuem um correlato fenomenológico, as categorias cenopitagóricas, a saber: primeiridade, segundidade e terceiridade. Na terceiridade encontramos as regularidades, as leis da natureza, as quais se manifestam na segundidade na forma de ação e, esta ação, por sua vez, só pode tomar lugar se precedida pela sensação, i.e., a primeiridade. Peirce foi também um historiador da filosofia e da ciência e dedicou, praticamente, toda sua vida ao estudo dos problemas enfrentados por ambas tradições. A perspectiva do Lógico de Milford não foi a de um aviador aventureiro, mas de um indivíduo que soube galgar sobre os ombros dos gigantes antes de atingir uma posição bem privilegiada, a partir da qual pudesse observar com clareza o vasto e complexo panorama da natureza que nos cerca e qual o papel das nossas crenças neste ambiente.

Peirce distingue quatro diferentes formas na aquisição de crenças: (1) o método da tenacidade, sustentar uma crença com afinco, apesar das evidências contra ela; (2) o método da autoridade, uma crença que é transmitida por um meio social e doutrinário; (3) o método a priori, onde escolhemos a crença que melhor compatibiliza com nossas demais crenças e, por fim; (4) o método científico, a crença resultante da investigação de uma comunidade de pesquisadores que compartilham o propósito de conhecer a verdade sobre os seus objetos de estudo ${ }^{29}$. Peirce foi treinado desde a infância por seu pai, Benjamim Peirce, para ser um cientista. Benjamim era, então, o mais renomado astrônomo e matemático dos Estados Unidos. A escolha do quarto método, o científico, não se deve somente a uma questão moral, pois, ao mesmo tempo, é uma decisão epistemológica. A juventude de Peirce foi intensamente ocupada por atividades em ciências como física, química, lógica, matemática, astronomia, entre outras.

Foi transitando entre estas disciplinas que Peirce se familiariza com a aproximação de Laplace à distribuição dos erros em observações experimentais. Louis Menand aponta para o fato de que os trabalhos de Laplace, assim como de outros matemáticos e astrônomos do início do século XIX, lançaram

\footnotetext{
${ }^{27}$ CP 5.311, 1868.

${ }^{28}$ CP 8.330, 1904.

${ }^{29}$ CP 5.377-387, 1877.
}

\begin{tabular}{|c|c|l|l|c|c|}
\hline intuitio & $\begin{array}{c}\text { ISSN } \\
1983-4012\end{array}$ & Porto Alegre & Vol.7 $-\mathrm{N}^{\circ} .2$ & $\begin{array}{c}\text { Novembro } \\
2014\end{array}$ & p. 134-145 \\
\hline
\end{tabular}


muita luz sobre a distribuição de resultado díspares em observações ${ }^{30}$. Essa aproximação aos erros se vale da regularidade nas variações das observações astronômicas sobre posições de corpos celestes. Curiosamente, as observações dos astrônomos costumam se apresentar como desvios em torno de um ponto, o qual pode ser determinado matematicamente por um denominador comum para todas as experiências observacionais. Esta é a conhecida "Teoria da distribuição dos Erros," a qual exibe, em um plano cartesiano, uma curva em forma de sino na variação das diferentes leituras astronômicas realizadas sobre condições variadas e por observadores ou equipes distintas. Dessa forma, determina-se uma posição para o corpo celeste mediado pelas observações precedentes. De acordo com Menand, a estatística conquista a incerteza incorporando-a ${ }^{31}$. Laplace também estende a aplicação da estatística aos fenômenos humanos, levado pela esperança de poder conhecer as leis desconhecidas que fazem certos eventos parecer randômicos e indeterminados. Em sua síntese, Laplace abriu o caminho da mecânica celeste para a mecânica social, entretanto, essa aproximação ainda é bastante carregada de determinismo e Peirce estava decidido, desde muito cedo, a se desviar de concepções mecanicistas.

A constatação de Peirce que no nosso universo é quase impossível reunir exatamente as mesmas condições duas vezes, mesmo em um laboratório, leva a sua incorporação da indeterminação e da incerteza quando falamos de leis e generalizações científicas, ainda que seja, como na avaliação de Chauncey Wright, somente nossa incerteza, nossa incapacidade de compreender as leis que se ocultam. Como alerta Menand, isto pode acarretar em nominalismo, ou ainda, na pior das hipóteses, sob a perspectiva de Peirce, em ceticismo. Dessa forma, Peirce tentar expor o erro dos nominalistas em tomar a formação da crença enquanto centrada no sujeito $^{32}$. Nesse momento, deparamo-nos com um de seus movimentos mais originais. Naturalmente, as crenças dos indivíduos são falhas e estes não podem ter acesso ao conhecimento preciso e objetivo da realidade. Entretanto, para Peirce, ao longo do tempo, uma comunidade pode ter acesso ao conhecimento e, para ilustrar sua concepção, põe sobre a mesa a Teoria dos Erros. Esse é o resultado da sua análise histórica das ciências e uma base para o seu falibilismo. Para salvaguardar o papel da lógica e o próprio conhecimento científico, Peirce recorre ao que foi aqui apresentado como suas categorias cenopitagóricas, a base fenomenológica para o seu realismo escolástico. As leis da natureza, ainda que sujeitas à incerteza, assim como os termos gerais (e não universais) da ciência, vão ter seu lugar na terceiridade, espaço reservado na metafísica de Peirce para aquelas coisas que não existem na segundidade, o aqui e o agora [hic et nunc], mas, mesmo assim, são reais, pois exibem efeitos causais sobre a nossa experiência.

\footnotetext{
${ }^{30}$ MENAND, L. (2001). The Metaphysical Club; a Story of Ideas in America. Nova York: Farrar, Straus and Giroux Eds., 2001, p. 182-3.

${ }^{31}$ MENAND, L. (2001). The Metaphysical Club; a Story of Ideas in America. Nova York: Farrar, Straus and Giroux Eds., 2001, p. 184.

${ }^{32}$ MENAND, L. (2001). The Metaphysical Club; a Story of Ideas in America. Nova York: Farrar, Straus and Giroux Eds., 2001, p. 228.
}

\begin{tabular}{|c|c|c|c|c|c|}
\hline intuitio & $\begin{array}{c}\text { ISSN } \\
1983-4012\end{array}$ & Porto Alegre & Vol.7 $-\mathrm{N}^{\mathrm{o}} .2$ & $\begin{array}{c}\text { Novembro } \\
2014\end{array}$ & p. 134-145 \\
\hline
\end{tabular}


A teoria dos erros se faz necessária na argumentação de Peirce, pois é resultado da experiência acumulada pela comunidade, a qual atesta que dois indivíduos não podem realizar a mesma observação de um fenômeno. Isto, na opinião de Menand, é a convicção sobre a qual repousa toda a filosofia de Peirce, ou seja, que o conhecimento não pode depender das inferências de simples indivíduos ${ }^{33}$. Isto fica claro na maneira como Peirce fundamenta o seu socialismo lógico sobre a noção de comunidade. Quando Peirce se preocupa em fornecer uma descrição da validade objetiva dos princípios lógicos da inferência (dedução, indução e hipótese) ele faz isso recorrendo aos seus conceitos característicos de verdade (como o acordo último da investigação), realidade (aquilo que é representado no acordo) e comunidade, enquanto o fundamento último da lógica e da realidade ${ }^{34}$.

\section{Considerações finais}

Efetivamente, o entorno social é um dos focos de atenção do pragmatismo clássico. A verdade, tanto para James como para Peirce, é uma noção que pressupõe uma comunidade e suas aplicações são mais úteis na medida em que essa comunidade seja o mais ampla possível. Esta é mais uma razão pela qual os pragmatistas não convertem o indivíduo no centro de sua filosofia. O indivíduo está muito mais propenso ao erro e a melhor estratégia para se progredir é reunir nossos esforços em um empreendimento social $^{35}$. É através desse tipo de comunhão simbólica que aprimoramos nossa capacidade inferencial. Sem o apoio de seu grupo, os indivíduos de uma comunidade epistêmica não seriam capazes de organizar seu conhecimento através de um sistema linguístico, sistema esse que, no meu entender, potencializa a capacidade computacional e inferencial. Estas características do conhecimento partilhado pelo senso comum e pela ciência são observadas no conceitual pragmatista. Mesmo assim, no interior do pragmatismo clássico não foi negligenciado o fato de que este sistema linguístico está suportado por um sistema de processamento simbólico, com uma estrutura própria e programas recebidos filogeneticamente.

Surge a partir daí um naturalismo que confronta e substitui as maneiras tradicionais de encarar a mente, rejeitando a ideia de um self como havia sido herdado do racionalismo e produzindo uma epistemologia e uma filosofia da mente mais abrangente, como também mais controvertida. Para o público presente nas primeiras conferências, toda esta ousadia, muitas vezes, ficava comprometida devido a uma certa obscuridade. Certa vez, comentou James a respeito das conferências de Peirce, que via naquilo tudo

\footnotetext{
${ }^{33}$ MENAND, L. (2001). The Metaphysical Club; a Story of Ideas in America. Nova York: Farrar, Straus and Giroux Eds., 2001, p. 229.

${ }^{34}$ DELANEY, C. F. (1984) The Journal of Speculative Philosophy Papers. (Intro) In: MOORE, E. C et al. (Eds.) The Writings of C. S. Peirce, vol. 2. Indiana Univ. Press, Bloomington, 1984, p. xli.

${ }^{35}$ MAYORGA, 2007, p. 309.
}

\begin{tabular}{|c|c|c|c|c|c|}
\hline intuitio & $\begin{array}{c}\text { ISSN } \\
1983-4012\end{array}$ & Porto Alegre & Vol.7 $-\mathrm{N}^{\mathrm{o}} .2$ & $\begin{array}{c}\text { Novembro } \\
2014\end{array}$ & p. 134-145 \\
\hline
\end{tabular}


algo como "relâmpagos liberados do interior de profundas trevas cimerianas"36. Ora, penso que podemos dizer algo semelhante de algumas conferências de James. Contudo, mesmo com brumas ao seu redor, creio que o pragmatismo clássico tem coisas bastante relevantes a nos dizer no que diz respeito a uma dimensão social do conhecimento.

De certa forma, o pragmatismo clássico aspirou por explicar como cada um de nós participa da experiência que temos em comum de um objeto, ou ainda, como chegamos a consensos ou concordâncias. Muitas vezes, no que toca a escolha entre teorias rivais não pesa somente critérios como simplicidade e coerência com nossas próprias crenças, mas também aquela que menos agride o senso comum. Um certo grau de concordância com o senso comum está implícita na noção jamesiana de concordância [agreement $^{37}$. Confrontando testemunhos podemos conceber um reforço social sobre as crenças. As teorias do conhecimento pragmatistas, tanto através da concepção reformada de Peirce quanto da tradição de James, continuam repercutindo e sendo aplicadas não somente em diversos campos do conhecimento científico e na crítica literária, mas também na sustentação de discursos políticos, na prática médica e na jurídica. Assim, facilmente percebe-se que estes programas de pesquisa não estão inseridos em uma tradição com hábitos esotéricos, mas que dialogam com diversas esferas da vida contemporânea.

\section{Referências}

BAIARDI, D. C. (2012) Intentionality, Fitness and Evolution in William James's Pragmatism. In: Cognitio-Estudos, V. 9, No 2, Julho-Dezembro, 2012, pp.102-110.

BRENT, J. (1993) Charles Sanders Peirce: A Life. Indiana University Press; Bloomington, 1993.

DELANEY, C. F. (1984) The Journal of Speculative Philosophy Papers. (Intro) In: MOORE, E. C et al. (Eds.) The Writings of C. S. Peirce, vol. 2. Indiana Univ. Press, Bloomington, 1984, pp. xxxvi-xlii.

DENNETT, D. C. (1982) Beyond Belief. In: WOODFIELD, A. (ed.) Thought and Object: Essays on intentionality. Oxford: Clarendon Press, pp. 1-95.

FODOR, J. A. (1980) Methodological Solipsism Considered as a Research Strategy in Cognitive Psychology. In: FODOR, J. A. Representations: Philosophical Essays on the Foundations of cognitive Science. Brighton: Harvester Press, 1981, pp. 225-253.

FREGA, R. (2011) Evolutionary Prolegomena to a Pragmatist Epistemology of Belief. In FREGA, R. (Ed.) Pragmatist Epistemologies. Lanham: Lexington Books, 2011, pp 127-52.

HOUSER, N. (2011) Peirce Post-Jamesian Pragmatism In: European Journal of Pragmatism and American Philosophy, 2011, III, 1, pp. 39-60.

JAMES, W. (1878) Remarks on Spencer's definition of Mind as Correspondence. In: Herbert Spencer, Contemporary Assessments - Herbert Spencer Collected Writings. Londres: Routledge \& Thoemmes Press, 1996.

(1907) Pragmatism's Conception of Truth. In: MCDERMOTT, J. J. (Ed.) The Writings of William James: A Comprehensive Edition. Chicago: The University of Chicago Press, 1977.

. The Principles of Psychology. Vol. I. New York: Henry Holt and Company, 1890.

LOVEJOY, O. A. (1909) Pragmatism and Realism. In: The Journal of Philosophy, Psychology and Scientific Methods, Vol. 6, No. 21, pp. 575-580.

MAYORGA, R. M ${ }^{a}$ P. (2007) El Pragmatismo: ¿Un Nombre Antiguo para Nuevas Maneras de Pensar? In: Anuario Filosófico, 2007 (40), pp. 301-318.

${ }^{36}$ HOUSER, N. (2011) Peirce Post-Jamesian Pragmatism In: European Journal of Pragmatism and American Philosophy, 2011, p. 53.

37 RORTY, R. (2006) Uma visão pragmática da filosofia analítica contemporânea. In: RORTY, R \& GHIRALDELLI, P. Ensaios pragmatistas: sobre subjetividade e verdade. Lamparina: Rio de Janeiro, 2006, p. 109.

\begin{tabular}{|c|c|l|l|c|c|}
\hline intuitio & $\begin{array}{c}\text { ISSN } \\
1983-4012\end{array}$ & Porto Alegre & Vol.7 $-\mathrm{N}^{\circ} .2$ & $\begin{array}{c}\text { Novembro } \\
2014\end{array}$ & p. 134-145 \\
\hline
\end{tabular}


MCDERMOTT, J. J. (1977) Introduction. In: MCDERMOTT, J. J. (Ed.) The Writings of William James: A Comprehensive Edition. Chicago: The University of Chicago Press, 1977.

MENAND, L. (2001). The Metaphysical Club; a Story of Ideas in America. Nova York: Farrar, Straus and Giroux Eds., 2001.

PEIRCE, C. S. (CP) Collected Papers of Charles Sanders Peirce (Ed. Digital) HARTSHORNE, C \& WEISS, P. (Eds.) Cambridge: Harvard University Press, 1931-1935. . (1878) How to Make Our Ideas Clear. In: Popular Science Monthly, v. 12, pp. 286-302.

PERRY, R. B. (1964) The Thought and Character of William James. Nashville: Vanderbilt Univ. Press, 1996.

PUTNAM, H. (1995) Permanência em James (Trad. de FOSCHIANI, C.) In: Cognitio-Estudos, V. 7, No 2, JulhoDezembro, 2010, pp. 210-220.

. (1997) Religious Faith, Intellectual Responsibility and Romance. In: PUTNAM, Ruth Anna (Ed.) The

Cambridge Companion to William James. Cambridge: Cambridge University Press, 1997.

RORTY, R. (2006) Uma visão pragmática da filosofia analítica contemporânea. In: RORTY, R \& GHIRALDELLI, P. Ensaios pragmatistas: sobre subjetividade e verdade. Lamparina: Rio de Janeiro, 2006, pp. 106-125.

WIENER, P. (1969) Evolution and the Founders of Pragmatism. Peter Smith: Gloucester, 1969.

Recebido em: 30/05/2014

Aprovado para publicação em: 21/08/2014

\begin{tabular}{|c|c|l|l|c|c|}
\hline intuitio & $\begin{array}{c}\text { ISSN } \\
1983-4012\end{array}$ & Porto Alegre & Vol.7- $\mathrm{N}^{\mathrm{o} .2}$ & $\begin{array}{c}\text { Novembro } \\
2014\end{array}$ & p. 134-145 \\
\hline
\end{tabular}

